\title{
Changes in the Social Networks of Three Women with an Intellectual Disability: A Qualitative Follow-Up Study
}

\author{
Minna Saarinen ${ }^{1}$, Laura Holm ${ }^{1} \&$ Lotta Uusitalo-Malmivaara ${ }^{1}$ \\ ${ }^{1}$ Faculty of Educational Sciences, University of Helsinki, Finland \\ Correspondence: Minna Saarinen, Faculty of Educational Sciences, University of Helsinki, Finland.
}

Received: January 19, 2018 Accepted: February 12, 2018 Online Published: March 8, 2018

doi:10.5539/jel.v7n3p76 URL: https://doi.org/10.5539/jel.v7n3p76

\begin{abstract}
There is ample evidence to show that people with intellectual disabilities (ID) face an increased risk of being socially excluded. The longer life expectancy of persons with ID carries new challenges. In this paper, we report on a follow-up case study of three Finnish women with ID. The women were interviewed twice (in 1995 and in 2013) and relationship maps were drawn pursuant to the interviews. In all three cases, the density of the relationship maps had decreased. In two cases, intimate relationships had remained or become even closer. In one case, intimate relationships were fewer. External services were inadequate in supporting the women to maintain their social relationships. Resources in the immediate families were decisive in determining their life course which was burdened by several extra obstacles. Some of these obstacles could possibly have been prevented if there had been a more permanent support system. The advantages and disadvantages of service and support paradigms are discussed.
\end{abstract}

Keywords: friendship, intellectual disability, relationship maps, service paradigm, social networks, support paradigm

\section{Introduction}

Where could I find a man who could tolerate me, believe in God and have an intellectual disability?

Emilia's interview

Functioning social relationships are crucial for quality of life and happiness (Diener \& Seligman, 2002; Schalock, $\&$ Brown et al., 2002). People who have close relationships and a wide social network have advantages in almost all life aspects. They enjoy greater security, support, trust, compassion, opportunities to find jobs and leisure activities, chances to participate in community activities and find deeper meaning in their lives (Seymour et al., 2009). Friends are an important part of life, helping us to become "whole", improve our well-being and giving us zest for life (Janney \& Snell 2006, p. 6). Respectively, loneliness causes major threats to one's overall well-being. These threats are not restricted to mental health but entail integration in society and also physical health (Hawkley, Thisted. Masi, \& Cacioppo, 2010).

\subsection{The Social Networks of People with Intellectual Disabilities}

Previous studies have shown that people with intellectual disabilities (ID), regardless of level of impairment, enjoy close meaningful friendships that fulfil social needs (Kersh, Corona, \& Siperstein, 2013). However, there is ample evidence to show that people with ID face an increased risk of being socially excluded and having fewer friends than other people (Bigby, 2008; Emerson \& Hatton, 2008). According to Gilmore and Cuskelly (2014), up to half of people with ID are chronically lonely, compared with around $15-30 \%$ of people in the general population. Typically, people with ID also suffer from mental health problems (in childhood, Einfeld, Ellis, \& Emerson, 2011; Uusitalo-Malmivaara et al., 2012, in adults, Bhaumik, Tyrer, \& McGrother, 2008) and various somatic symptoms (O'Hara, McCarthy, \& Bouras, 2010) much more frequently than those without ID. These factors substantially reduce their ability to create and maintain social relationships. Feeling lonely may pave the way to non-favourable lifestyles including overeating, smoking or substance abuse (Jobling \& Cuskelly, 2006). These may further weaken the capability of making friends and lead to chronical loneliness over time. It is clear that persons whose life opportunities are already constrained by cognitive and health factors are especially vulnerable to outcomes caused by unsatisfactory social experiences. Furthermore, people with severe ID have fewer relationships than people at the mild end of the spectrum (McLean, Brady, \& McLean, 1996). 
Often the relationships are predominantly with paid workers or one's family (Johnson, Douglas, Bigby, \& Iacono, 2010; Robertson et al., 2001). Thus, the thinness of social networks in people with the most severe IDs is of particular concern. However, generalized statements about the "disabled life course" or development of social networks cannot be made (Priestley, 2001).

\subsection{Aging with Disability}

The longer life expectancy of persons with ID carries new challenges in the 21st century (Shoostari, Naghipur, \& Zhang, 2012). The inequalities that persons with ID experience can become more pronounced during the process of aging (Heller \& Heuman, 2013; Phillipson \& Baars, 2007). Knowledge and models are needed to take care of this growing population. Social relationships are drastically jeopardized if they rely solely on a person's parents and their capacity to affiliate. Historically, people with ID have been isolated from general society, which has restricted their opportunities to participate (Heller \& Heumen, 2013). Being dependent on one's elderly parents in middle age poses similar risks (Johnson, Traustadottir, Harrison, Hillier, \& Sigurjonsdottir, 2001). An obvious prerequisite for social association is the opportunity to meet other people. The form of service delivery plays a crucial role in promoting social encounters. In the service paradigm (Smull \& Bellamy, 1991), persons with ID are directed towards specialized institutions, such as sheltered workshops, day-activity programs, and other leisure programs. In this model, persons with ID are often totally dependent on others' help in getting connected. Frequently, persons with ID call their therapists, social workers or aids their closest friends (Joblin, Moni, \& Nolan, 2000; Kennedy, 2001). However, these relationships are characterized by a professional approach and do not meet the criteria of mutual, reciprocal friendships. According to studies by McVilly et al. (2006), many individuals with ID found that their friends, and especially their best friend, to be among those who also had ID. This was explained by there being sufficient equality among peers and being void of the rejection experienced with persons with no ID. Although the service paradigm seems to promote encounters between persons with ID, friendships are not guaranteed. Also, the chances to make friends with persons with no ID are often limited to hired workers. In the service paradigm, parents are often the advocates who organize activities for the person with ID. When parents grow old themselves, encounters with the surrounding world may be reduced to a minimum (Heller, Caldwell, \& Factor, 2007).

In the support paradigm (van Loon et al., 2010; see also Thompson et al., 2009), persons with ID can be integrated in the general labour market when the proportion of workers with ID does not exceed the natural proportions in the community. Several advantages exist in this model, including better financial outcomes, increased personal growth, adaptation of services according to people's needs, and greater social integration of people with ID (Migliore, Mank, Grossi, \& Rogan, 2007). However, disadvantages are also apparent, such as discontinuity of work especially in times of economic recession, and personal safety of persons with ID. Furthermore, social relationships with co-workers may be fewer when compared with those developed in sheltered workshops. As an outcome, the support paradigm can promote loneliness in a deeper sense than the service paradigm; being among other people but feeling excluded (Johnson, Douglas, Bigby, \& Iacono, 2012).

Thus, both paradigms pose problems in the social integration of persons with ID. The chances of getting to know a person are scarce if surrounded by only a few other people. Nevertheless, having only a small number of friends is not necessarily a sign of loneliness. Conversely, being surrounded by and having interaction with many people does not guarantee the most important aspect of friendship: emotional connectedness (Johnson et al., 2012). Forming intimate, romantic relationships is a dream of most individuals, including those with ID. Finding a partner may be a challenge and marriages occur less frequently than in the general population (Hall et al., 2005). Wishing to have a romantic relationship, but having it go unsatisfied certainly is a cause of stress and decrease in happiness.

The purpose of the present study is to describe and analyse the change in social networks in three women with ID over a period of almost two decades. This is one of the few qualitative follow-up studies focusing on detailed social relationships of persons with ID. Specifically, we sought to address two questions with respect to the change in social relationships. First, the richness of the social relationships: has the density of the social network maps changed? Second, intimacy of the relationships: has the closeness in social relationships changed? Plausible causes for the observed trajectories are discussed in the light of the service or support paradigm.

\section{Method}

\subsection{The Participants and Data Collection}

A purposive sampling method was used (Patton, 2002). Our informants were three women, Maria, Emilia and Linnea (pseudonyms). In 1995, they participated in an On-Campus supported adult education program aimed at tailoring the individual educational system for people with disabilities studying at a university or a vocational 
school in Finland (Pierce, 2001; Uditsky et al., 1998). Our informants were among the first students to be accepted into the On-Campus program. The regional social workers recruited them based on families' willingness to find an inclusive study setting. The first author of the current study conducted the initial multiple interviews during the On-Campus time. A detailed description of the participants' recruitment process and the analysis of social networks from the first interviews have been provided elsewhere (Saarinen, 2012). In 2013, the women were contacted again. A three-membered research team conducted the individual interviews at their homes or in a university office. In both 1995 and 2013, interviews were based on the participation section of the interview method called OVAALI (Saloviita, 1995) aimed at evaluation and development of the quality of disability services (Table 1). Furthermore, every participant had a relationship map (Enos, 1995), filled out in pursuance of the interviews. The participants, accompanied by members of their family, independently determined where a nominated name was placed on the relationship map, and the researcher acted as a secretary on these occasions. The map has four fields: family, friends, members of communities, and authorities (Barnett \& Parker, 1995; Seikkula, 1994, p. 22). The names of those closest to the person are written closest to their name, while those who are not so close are listed further away (see Figures 1-3).

Table 1. Questions adapted from OVAALI interview's participation section (Saloviita, 1995, p. 59)

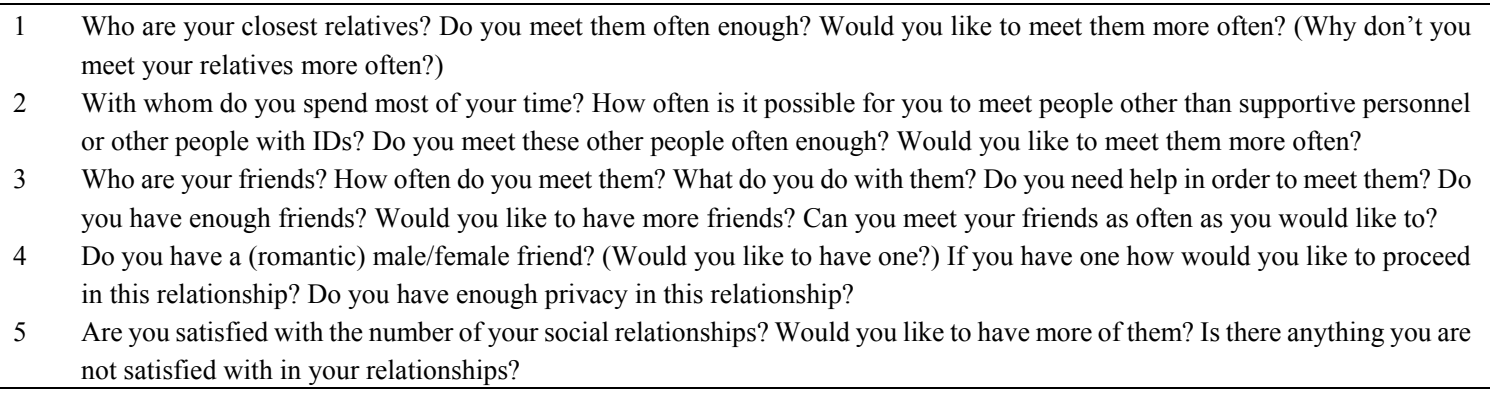

\subsection{Data Analysis}

Data were analysed by the first author using qualitative content analysis (Hsieh \& Shannon, 2005; Patton, 2002). The interviews were transcribed, coded and categorized according to our two research questions, the richness and the intimacy of the relationships. The nature and reciprocity of the relationships were analysed, as were the frequency and chances for social encounters. Text analysis was carried out using a traditional colouring method. The themes were combined to form subcategories. The two other authors of the paper confirmed the categorization. The relationship maps were drawn in detail based on the interviews and the researchers' memoranda. The importance and meaning of every person mentioned on the map was interpreted with help of the interview categories. In particular, interpretation of the intimacy of the relationships was based on the interview data. E.g., a relative drawn as seemingly distant on the map in reality could be an important supporter and a friend. Also, the density of persons in each sector of the map was quantified. The same protocol was applied to both measurement times, in 1995 and 2013. The maps were compared in order to discover the change in relationships. The names (pseudonyms) are written in the maps in the way they were mentioned by the respondents. In some cases, only the category of the person (e.g., neighbour) was given.

\section{Findings}

The development of social relationships of each of our three informants is presented separately.

\subsection{Maria}

Maria has a diagnosis of mild intellectual disability. In 1995, she was 17 years old. She lived in an urban area with her parents, twin sister and other siblings. She studied the clothing industry at a vocational school and worked as a trainee in a weaving centre. In 2013, Maria was 35 years old and she had an 8-year-old daughter. She lived with her mother and child in a city of 130000 inhabitants. She had studied a second profession and now worked as a cleaner in a preschool. 

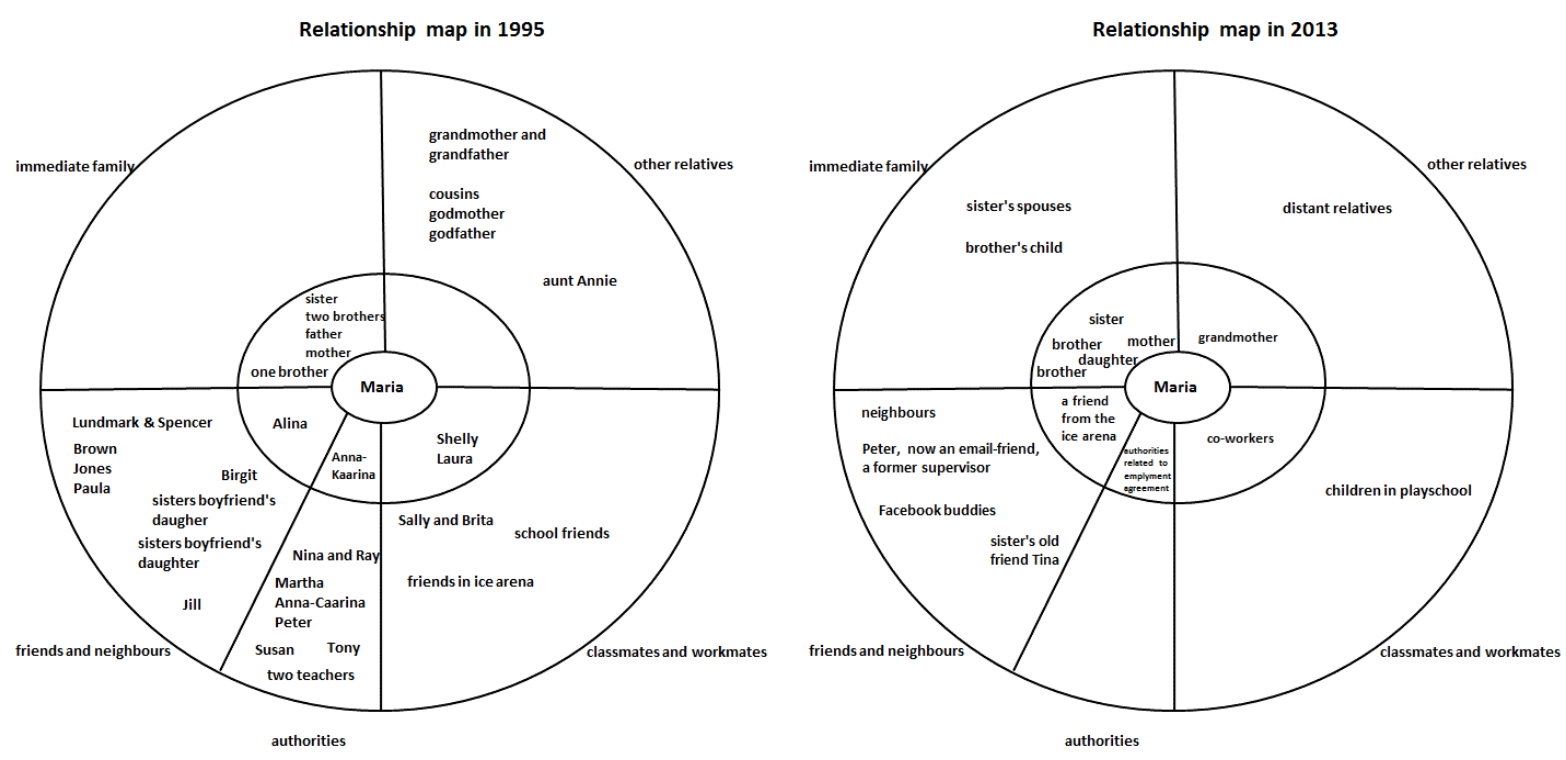

Figure 1. Maria's relationship maps in 1995 and in 2013

In 2013, Maria's map shows two major changes in the immediate family sector. First, and most importantly, following sexual abuse she had become the mother of a daughter. Maria had no connection with the father of her child. Second, Maria's own parents were divorced and, later her father had died. Maria still lived in her childhood home with her mother. Maria partly participated in the school activities of her daughter. However, Maria's mother was the primary custodian of the little girl. Maria felt close to her non-disabled twin sister and her two brothers with their families, whom she met many times a week. The children of her brothers had become important to her.

According to Maria's mother:

The daughter probably is the number one for Maria, and perhaps our Lisa (Maria's sister). And, unfortunately (laughs), the mom, too.

The relatives sector shows that Maria's elderly grandmother had become more significant over time. Other relatives were distant, as they had been in 1995. Some of the friends and assisting personnel from the old times still remained as her Facebook friends. In 2013, Maria worked in a kindergarten. Her occupation corresponded to her education and she loved her job. The other workers were mainly her colleagues, not true friends, and she seemed to be only partly integrated into the work community. Nevertheless, the meaning of work was obvious for Maria. Her mother stated:

For Maria, it's terribly difficult to stay at home while being sick. Not being able to go to work makes her cry.

However, Maria did not seem to be too close with the children in the kindergarten either.

Some of the kids talk to me, I think. Though, I don't know their names.

The authorities provided services Maria on occupational issues. The support personnel Maria had in 1995 no longer seemed to be involved in her life. The friends sector showed changes in both the density and intimacy of the relationships. In 1995, there seemed to be a wider variety of people around her. Now, more distant friends were mentioned, and some neighbours. The four friends with ID illustrated on the map in 1995 were no longer mentioned in 2013. In 1995, Maria had also enjoyed the company of a non-disabled girl. This girl, Alina, was no longer part of Maria's life. Later, while studying for a second profession, she had found a new girlfriend. The name of this girl was not revealed. In 1995, Maria spent a lot of time at ice hockey arenas watching games. Before her daughter was born, she used to travel around with the fan club of her favourite ice-hockey team. Being a keen fan had brought her friends and acquaintances through the years. Ice hockey, Maria's long-term passion, was still part of her life in 2013.

Overall, Maria's social networks had remained rich and many-sided, although the mesh had grown in size. She was able to make friends and meet them autonomously. No romantic companion was mentioned. Maria seemed to enjoy particularly close and warm relationships with her extended family. 


\subsection{Emilia}

Emilia was diagnosed as having a moderate intellectual disability. In 1995, she was 20 years old. She studied home economics at a social sciences school. She trained for a profession in a cafeteria and in a school. Emilia lived in a rural area with her parents who held strict religious convictions.

In 2013, after years of unemployment and both somatic and mental disorders, Emilia was retired and living in a shelter home meant for persons with ID. She had been a keen painter but had largely given up this hobby. She had a dog which she walked in nearby parks. She also reported going shopping and visiting a few people, with her support person. Participation in a religious festival was a meaningful yearly activity for her. Overall, the bipolar mental disorder affected her profoundly, making her feel lonely and powerless. In the shelter home, she had opportunities to make friends, but she had become cautious and even suspicious towards her chances to become closely acquainted. However, she had a longing for a more intimate companion, as stated by her citation that starts this paper.

Where could I find a man who could tolerate me, believe in God and have an intellectual disability?
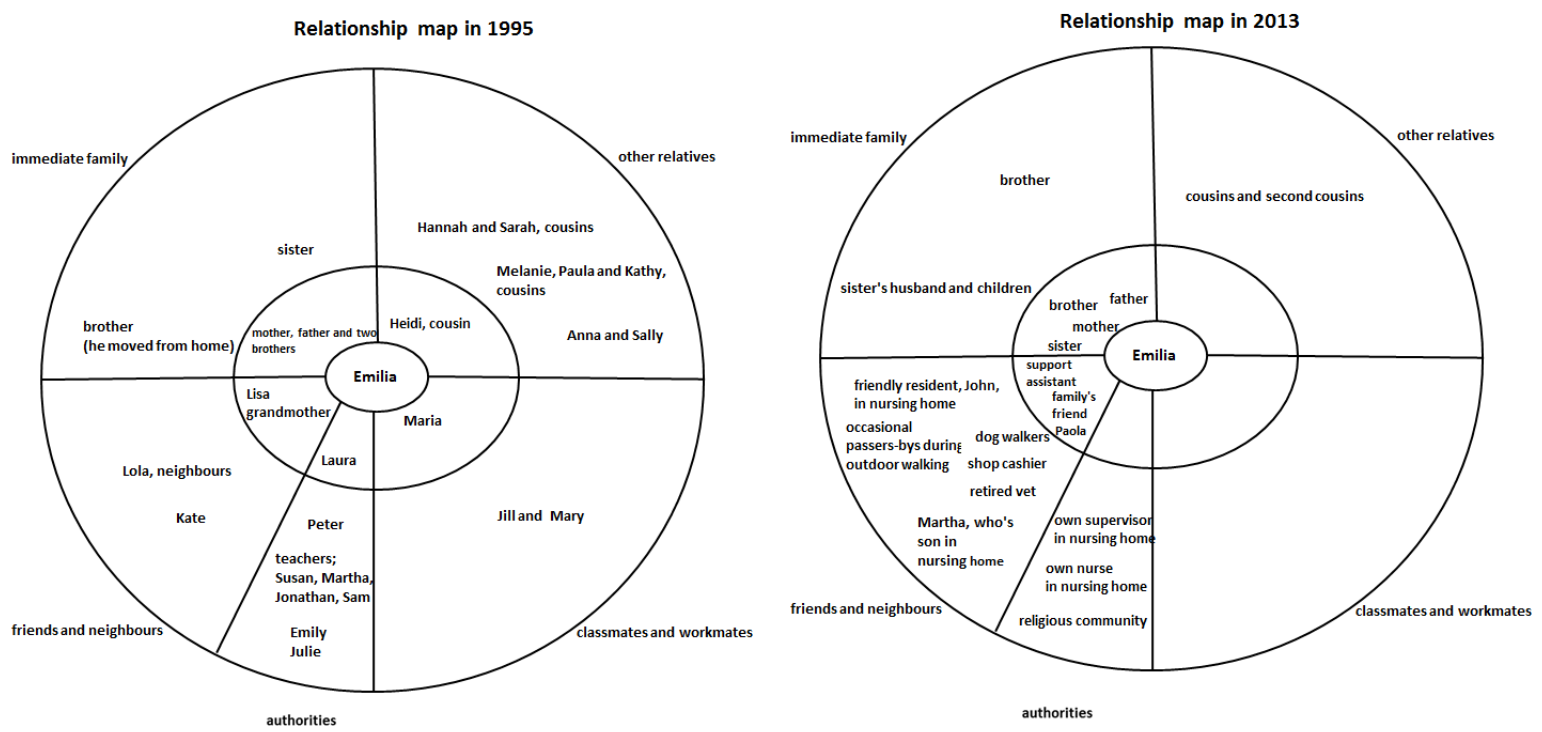

Figure 2. Emilia's relationship maps in 1995 and in 2013

The changes in Emilia's relationships show clearly in the maps. She still visited her childhood home regularly, and the relationships with her parents seemed close, as did the relationships with her brothers and sister. However, due to the illness of her aging mother, visiting had become less frequent. The best thing Emilia knew were family parties when "everybody was present". Religious meetings were important to the family but rare nowadays. Bonds with relatives had loosened up, mainly due to the poor condition of her mother. In the shelter home, her dog was her best friend. Walking the dog in a nearby park was her main hobby. Occasionally, she also met other people while outdoors. However, she had no close friends. She mentioned being lonely and unhappy.

There are few moments when I feel happy. In the shelter home, one cannot be happy when one does not know what the other inhabitants think of you.

The immediate family sector seemed similar to the one in 1995, but meetings had become rarer. The other relatives sector showed a drastic loss of relationships. She did not meet her cousins very often, and Anna, a close aunt, had passed away, which Emilia felt very sad about. Emilia had befriended some other students in 1995. However, none of these friendships had persisted and the schoolmates sector was empty. In the shelter home, she had a male neighbour, a polite and nice elderly gentleman, John. Emilia met John every day, but she was hesitant to call John her close friend. Occasionally, Emilia engaged in activities with other residents in the shelter home, she got together with other dog-walkers, and mentioned a nearby shop cashier as an acquaintance. Overall, she felt shy and reluctant to start talking to people.

Emilia sighted: 


\section{Well, I don't have friends.}

Her mother continued:

It really is saddening that Emilia has no friends...

Emilia had helping hands around her in the shelter home. She got along with them quite well, however these people could not be called friends. She appreciated one long-term supervisor, in particular:

\section{No-one could be more understanding and patient than Rosa!}

To summarize, Emilia's relationship map mainly consisted of her immediate family and authorities. Her parents remained close to her, but she didn't see them as often as she wished. Bipolar disorder and physical problems plagued Emilia and made socializing difficult.

\subsection{Linnea}

Linnea has Down's syndrome and has been diagnosed as being of moderate intellectual disability. In 1995, she was a 35-year-old social services student, living with her mother. Her father had died earlier on. In 2013, at the age of 52, she still lived with her elderly mother in the same house outside a city. Physical problems such as a broken elbow that could not be healed, made her life difficult. Linnea needed help to get dressed, eat and other basic daily routines. However, she was able to enjoy visiting an activity centre. There she worked once-a-week and although being withdrawing, felt like a welcomed person. According to her mother, she had always been shy. Due to her mother's lack of resources, visits were rarer than Linnea would have wanted then to be. Besides visits to the centre, Linnea enjoyed playing with an eight-year-old boy who she called her best friend. She even stayed overnight in the little boy's home. Linnea's mother said Linnea liked being in the countryside, gardening, making coffee, eating treats, and watching TV. Scrapping paper was her special hobby, demonstrating her appreciation of beauty. Recalling memories with the help of photo albums was an important leisure time activity for both Linnea and her mother. Neither relatives nor friends were seen very often. According to mother, her relatives had not accepted Linnea. Her mother said:

\section{The relatives are the worst!}

In 1995, the relatives were mentioned "as friends". However, this was not the case anymore. A female aid who drove Linnea to the activity centre had become important to her. Also, she felt warmly towards an assistant at the centre. Her mother's long-term friends were among the few persons Linnea met. Some of these elder couples had taken care of Linnea over several tens of years. Paul, an ex-relative, was mentioned as being especially important. Her motherpraised Paul:

\section{He has always appreciated Linnea.}
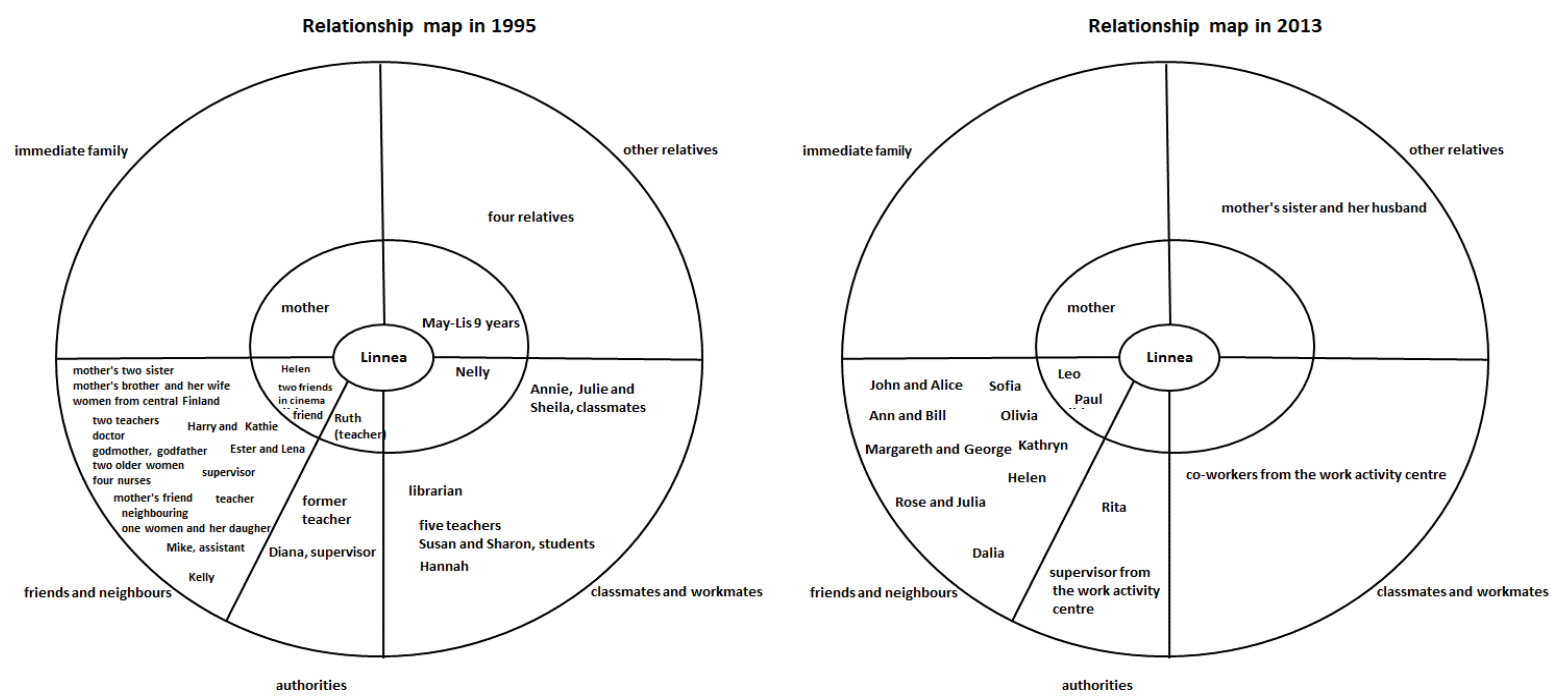

Figure 3. Linnea's relationship maps in 1995 and 2013

Linnea's social connections were totally dependent on her mother and the mother's friends. Linnea had no autonomous relationships with other people. Her mother said: 


\section{Linnea's pals are those I have the strength to be in contact with.}

Linnea's maps had become thin and filled with older people. In 1995, Linnea and her mother had become friends with some authorities, like a doctor, a teacher and an assistant. These persons were not visible on the newer map. Only one female nurse had remained a friend of the family.

\section{Summary of Findings and Discussion}

In this study, we sought to study changes in density and intimacy in social networks in three women with ID. Our informants were interviewed twice, in 1995 and in 2013. Both times, relationship maps were drawn, based on interviews and the researchers' notes, and finally, the maps were compared in detail. Overall, in all three cases, the density of the maps had decreased. In two cases, intimate relationships remained or had become even closer. In one case, intimate relationships were few. Next, we describe the development of relationships of each woman and discuss the potential reasons for the observed changes, in light of service and support paradigms.

The importance of the immediate family is underlined in our study. This comes as no surprise. However, it is disappointing to document that no external aid, be it part of the service or support paradigm, could guarantee a satisfactory life with meaningful social relationships for two of our participants. Only Maria seemed to have maintained an active social life and managed to occupy herself. Her first profession in the textile industry had not proved to be successful, but the second profession as a cleaner had brought her a permanent job in a kindergarten. Being part of the work community clearly meant a lot to her, although the adult relationships did not seem too close there. In particular, she enjoyed the company of the kindergarten children. In addition, Maria had maintained the same hobby throughout the years; that is, she still followed ice hockey and went to arenas to cheer her favourite team and meet other fans. The year-long continuation of an activity involving plenty of other people predicts at least some level of companionship and social inclusion (e.g., Simplican, Leader, Kosciulek, \& Leahy, 2015). This was true in Maria's case.

Maria had a child but no spouse. However, it would be misleading to call her a single mother, since her own mother, the grandmother of the child, lived with them and took care of them. Her siblings were very close to Maria. She was lucky to meet them several times a week. Furthermore, the siblings' families and friends extended Maria's social network and she was part of their lives in many ways. In addition to the birth of her daughter, a major change in Maria's close relationships was the death of her beloved father. Loss of the father was painful for Maria, but she seemed to gain resilience through her family's support. Also, the unwanted pregnancy seemed to have turned into happiness of being a mother. Maria's family members had long lived in the same urban neighbourhood close to each other. Maria was able to use the public transport system, making visiting easy.

To summarize, Maria's social relationships were satisfactory in many ways. The greatest contributing factor was the big family, and most influentially, her mother. Maria's life course could have been changed in a totally different direction after the childbirth, had her mother not been able to take care of both of them. Maria seemed included in many ways. Her work and other activities functioned well due to natural support in various settings.

Emilia's life seemed very different from that of Maria's. Living in a shelter-home did not foster Emilia's needs to belong or to contribute. Furthermore, health problems, depression in particular, plagued her. She longed for her family, but admitted that she would not be able to live there. Her elderly parents were not able to take care of her. Also, visiting was difficult due to the poor transportation system from the shelter home to her parents' home. Hobbies were limited to walking the dog, and occasionally going shopping. Emilia had been a keen painter, but the arts were no longer a source of joy to her. She seemed completely dependent on organized help. Her relationship map had become thin, and almost totally void of friends. Being a member of a Christian community also seemed to be a burden. Although not clearly stated, family no longer seemed to enjoy their church. On the contrary, there seemed to be mistrustful and feelings of rejection by the religious community. Emilia expressed a wish to find a close companion. However, she was not willing to accept the other inhabitants of the shelter home to become her friends. Her even cynical comments revealed an attitude of giving up. Who could like me? Only the dog. Feeling very lonely surely affected her mental health. Not even the support person in the shelter home had succeeded in binding tighter networks to her.

Our third informant, Linnea, suffered from multiple physical health problems. She was no longer able to cloth herself and moving was difficult. In the latter interview, she did not speak herself, but her mother answered on her behalf. Bonding with the mother had become very tight. The mother stated that the two of them spent too much time together and quarrels were frequent. Although we couldn't hear Linnea speak, her face revealed that she followed the convinersation and had an opinion of her own. Though shy, it seemed as if Linnea enjoyed the company of other people, even in the interviewers. Unfortunately, just getting out of the house had become too 
demanding a task for the two of them. Help was restricted to aiding Linnea in being transported to the activity centre once a week. Linnea's life-course shows a path of accumulating risks leading to an isolated lifestyle. In 1995, she was capable and willing to work, but some unfortunate incidents led her to leaving her job. The exact nature of these incidents was not clearly explained by the mother.

Risky and supportive factors were already visible in the three women in 1995. After almost two decades with plenty of obstacles, many of the outcomes could have been foreseen. Maria had an unwanted pregnancy; Emilia had become mentally ill; and Linnea had suffered a multitude of accidents leading to severe physical handicaps. Previous research shows that people with ID are in greater danger of feeling lonely, being sexually exploited, and having both mental and physical illnesses (Bhaumik et al., 2008; O'Hara et al., 2010). The strengths and vulnerabilities in social relationships became tangible in all three cases. Maria's extended family supported her heavily and her job gave her great satisfaction. However, it was made clear by her mother that a lot of bureaucracy and fighting for one's rights had occurred, in order to receive a job and payment for it. Emilia suffered a quite a different fate. Her disabilities were not much more severe than those of Maria, but the support she received turned out to be insufficient. Most of all, she lacked people advocating for her when needed. Her parents didn't have the mental or physical resources needed to guide her. Neither did professional aid come to help when she lost one job after one another. The religious community could have been a source of strength, but for reasons not revealed, the community seemed more of a worry. Emilia didn't like living in the shelter home but admitted not being able to live with her parents, either. Linnea got the minimum of help. Dependence on the 80 -year-old mother made life hard for both of them.

The current study has its limitations. First, studying the quality of relationships in persons with ID is challenging, since acquiescence may affect reporting (Finlay \& Lyons, 2002). In Linnea's case, the mother was the spokeswoman and Linnea's own opinion could not be clearly heard. Second, filling out the network maps and interpreting the positioning of people and the intimacy of relationships can be arbitrary. However, the three authors of the study agreed on the final design of the maps.

To conclude, our results show that support could have been directed more efficiently, taking into account the age and abilities the parents already had when the women were children. The childhood families' active lifestyle and parental networks clearly predicted the outcomes visible in our informants almost two decades later. A long-term guardian of interests for Emilia and Linnea may have been able to pave the way for a more versatile and fulfilling life from youth to middle age. In Emilia's case, representing a minority inside a minority, the strict Christian community multiplied her risks. Combining elements of both service and support paradigms and creating adaptive personalized services could have helped Emilia and Linnea to both widen and strengthen their social networks. In Maria's case, warm family relationships and being able physically to reach family members was of great benefit.

Our results indicate a need for further research on flexible new solutions to support social bonding of persons with ID. Models that take into account risky and supportive factors ought to be tested in a controlled manner. Our follow-up study clearly showed the predictability and vulnerability of the current service systems. In the end, only the immediate family seemed to matter. Equality and opportunities to participate in society (as stated in the United Nations' Convention on the rights of persons with disabilities (United Nations, 2007), had not come true.

\section{References}

Barnett, B., \& Parker, G. (1995). A test of the social support hypothesis. In T. S. Brugha (Ed.), Social Support and Psychiatric Disorder. Research Findings and Guidelinen for Clinical Practice. Great Britain: University of Cambridge.

Bhaumik, S., Tyrer, F. C., McGrother, C., \& Ganghadaran, S. K. (2008). Psychiatric service use and psychiatric disorders in adults with intellectual disability. Journal of Intellectual Disability Research, 52(11), 986-995. https://doi.org/10.1111/j.1365-2788.2008.01124.x

Bigby, C. (2008). Known well by no-one: Trends in the informal social networks of middle-aged and older people with intellectual disability five years after moving to the community. Journal of Intellectual and Developmental Disability, 33(2), 148-157. https://doi.org/10.1080/13668250802094141

Bigby, C. (2012). Social inclusion and people with intellectual disability and challenging behaviour: A systematic review. Journal of Intellectual and Developmental Disability, 37(4), 360-374. https://doi.org/10.3109/13668250.2012.721878

Bogdan, R. C., \& Biklen, S. K. (1982). Qualitative research for education: An introduction to theory and methods. Boston: Allyn and Bacon. 
Brygman, A., \& Burgess, R. G. (1994). Analyzing qualitative data. London and New York: Routledge.

Diener, E., \& Seligman, M. E. (2002). Very happy people. Psychological Science, 13(1), 81-84. Retrieved from http://journals.sagepub.com/doi/pdf/10.1111/1467-9280.00415

Einfeld, S. L., Ellis, L. A., \& Emerson, E. (2011). Comorbidity of intellectual disability and mental disorder in children and adolescents: A systematic review. Journal of Intellectual and Developmental Disability, 36(2), 137-143. https://doi.org/10.1080/13668250.2011.572548

Emerson, E., \& Hatton, C. (2008). Self-reported well-being of women and men with intellectual disabilities in England. American Journal on Mental Retardation, 113(2), 143-155. https://doi.org/10.1352/0895-8017(2008)113[143:SWOWAM]2.0.CO;2

Enos, J. (1995). Building relationships with friends and other community members. In J. M. Everson (Ed.), Supporting young adults who are dead-blind in their communities. A transition planning guide for service providers, families, and friends (pp. 185-201). Baltimore: Paul H. Brookes.

Finlay, W. M., \& Lyons, E. (2002). Acquiescence in interviews with people who have mental retardation. Mental Retardation, 40(1), 14-29. https://doi.org/10.1352/0047-6765(2002)040<0014:AIIWPW >2.0.CO;2

Gilmore, L., \& Cuskelly, M. (2014). Vulnerability to loneliness in people with intellectual disability: an explanatory model. Journal of Policy and Practice in Intellectual Disabilities, 11(3), 192-199. https://doi.org/10.1111/jppi.12078

Hall, E. (2005). The entangled geographies of social exclusion/inclusion for people with learning disabilities. Health \& Place, 11(2), 107-115. https://doi.org/10.1016/j.healthplace.2004.10.007

Hawkley, L. C., Thisted, R. A., Masi, C. M., \& Cacioppo, J. T. (2010). Loneliness predicts increased blood pressure: 5-year cross-lagged analyses in middle-aged and older adults. Psychology and Aging, 25(1), 132. https://doi.org/10.1037/a0017805

Heller, T., \& van Heumen, L. (2013). Aging and disability. In M. L. Wehmeyer (Ed.), The Oxford Handbook of Positive Psychology and Disability. Oxford: Oxford Library of Psychology.

Heller, T., Caldwell, J., \& Factor, A. (2007). Aging family caregivers: Policies and practices. Developmental Disabilities Research Reviews, 13(2), 136-142. https://doi.org/10.1002/mrdd.20138

Hsieh, H. F., \& Shannon, S. E. (2005). Three Approaches to Qualitative Content Analysis. Qualitative Health research, 15(9), 1277-1288. https://doi.org/10.1177/1049732305276687

Janney, R., \& Snell, M. E. (2006). Social relationships and peer support. Baltimore: MD: Paul H. Brookes.

Jobling, A., \& Cuskelly, M. (2006). Young people with Down syndrome: A preliminary investigation of health knowledge and associated behaviours. Journal of Intellectual and Developmental Disability, 31(4), 210-218. https://doi.org/10.1080/13668250600999186

Johnson, H., Douglas, J., Bigby, C., \& Iacono, T. (2010). The pearl in the middle: A case study of social interactions in an individual with a severe intellectual disability. Journal of Intellectual and Developmental Disability, 35(3), 175-186. Https://Doi.org/10.3109/13668250.2010.501026

Johnson, H., Douglas, J., Bigby, C., \& Iacono, T. (2012). Social interaction with adults with severe intellectual disability: Having fun and hanging out. Journal of Applied Research in Intellectual Disabilities, 25(4), 329-341. https://DOI:10.1111/j.1468-3148.2011.000669

Johnson, K., Traustadottir, R., Harrison, L., Hillier, L., \& Sigurjonsdottir, H. B. (2001). 17 The possibility of choice: women with intellectual disabilities talk about having children. Disability and the Life Course: Global Perspectives, 206.

Kennedy, C. H. (2001). Social interaction interventions for youth with severe disabilities should emphasize interdependence. Developmental Disabilities Research Reviews, 7(2), 122-127. https://doi:10.1002/mrdd.1017

Kersh, J., Corona, L., \& Siperstein, G. (2013). Social wellbeing and friendship of people with intellectual disability. The Oxford handbook of positive psychology and disability (pp. 60-81). Oxford: Oxford University Press.

McLean, L. K., Brady, N. C., \& McLean, J. E. (1996). Reported communication abilities of individuals with severe mental retardation. American Journal on Mental Retardation, 100(6), 580-591. 
McVilly, K. R., Stancliffe, R. J., Parmenter, T. R., \& Burton-Smith, R. M. (2006). "I get by with a little help from my friends": Adults with intellectual disability discuss loneliness. Journal of Applied Research in Intellectual Disabilities, 19(2), 191-203. https://doi:10.1111/j.1468-3148.2005.00261.x

Migliore, A., Mank, D., Grossi, T., \& Rogan, P. (2007). Integrated employment or sheltered workshops: Preferences of adults with intellectual disabilities, their families, and staff. Journal of Vocational Rehabilitation, 26(1), 5-19. https://doi=10.1.1.690.4321 \&rep=rep1\&type=pdf

O'Hara, J., McCarthy, J., \& Bouras, N. (2010). Intellectual disability and ill health: a review of the evidence. Cambridge: Cambridge University Press.

Patton, M. Q. (2002). Two decades of developments in qualitative inquiry: A personal, experiential perspective. Qualitative Social Work, 1(3), 261-283. https://doi.org/10.1177/1473325002001003636

Phillipson, C., \& Baars, J. (2007). Social theory and social ageing. Ageing in Societies, 68-84. https://doi.org/10.4135/9781446278918.n4

Pierce, K. (2001). A Healthy, Thoughtful, insightful discussion about social inclusion in a postsecondary institution. A doctor of philosophy in special education. Edmonton: Alberta in fall.

Priestley, M. (Ed.). (2001). Disability and the life course: Global perspectives. Cambridge: Cambridge University Press.

Robertson, J., Emerson, E., Gregory, N., Hatton, C., Kessissoglou, S., Hallam, A., \& Linehan, C. (2001). Social networks of people with mental retardation in residential settings. Mental Retardation, 39, 201-214.

Saarinen, M. (2012). Framework of social life. The social life of Campus-program students in their supported adult learning and leisure. A doctor of philosophy in special education. University of Jyväskylä, Jyväskylä Studies in Education, Psychology, and Social Research.

Saloviita, T. (1995). Osallistuminen, valinnanvapaus, arvostus, aktiivisuus, läsnäolo, itsenäisyys. Vammaispalvelujenlaadunarviointi ja kehittäminen. [Assessment and development of services for persons with IDs]. Jyväskylä: Yliopistopaino.

Schalock, R. L., Brown, I., Brown, R., Cummins, R. A., Felce, D., Matikka, L., \& Parmenter, T. (2002). Conceptualization, measurement, and application of quality of life for persons with intellectual disabilities: Report of an international panel of experts. Mental Retardation, 40(6), 457-470. https://doi:10.1352/0047-6765(2002)040\&lt;0457:CMAAOQ\&gt;2.0.CO;2

Seikkula, J. (1994). Sosiaaliset verkostot. Ammattiauttajan voimavara kriiseissä. [Socialnetworks. Empowering professional helpers in crisis]. Helsinki: Kirjayhtymä.

Seymour, H., Reid, G., \& Bloom, G.A.2009. Friendship in inclusive physical education. Physical Activity Quarterly, 26(3), 201-219. https://doi.org/10.1123/apaq.26.3.201

Shooshtari, S., Naghipur, S., \& Zhang, J. (2012). Unmet healthcare and social services needs of older Canadian adults with developmental disabilities. Journal of Policy and Practice in Intellectual Disabilities, 9(2), 81-91. https://doi:10.1111/j.1741-1130.2012.00346.x

Simplican, S. C., Leader, G., Kosciulek, J., \& Leahy, M. (2015). Defining social inclusion of people with intellectual and developmental disabilities: An ecological model of social networks and community participation. Research in Developmental Disabilities, 38, 18-29. https://doi10.1016/j.ridd.2014.10.008

Smull, M. W., \& Bellamy, G. T. (1991). Community services for adults with disabilities: Policy challenges in the emerging support paradigm. Critical issues in the lives of people with severe disabilities, 527-536.

Thompson, J. R., Bradley, V. J., Buntinx, W. H. E., Schalock, R. L., Shogren, K. A., \& Snell, M. E. et al. (2009). Conceptualizing supports and the support needs of people with intellectual disability. Intellectual and Developmental Disability, 47, 135-146. https://doi.org/10.1352/1934-9556-47.2.135

Uditsky, B., Frank, S., Hart, L., \& Jeffery, S. (1988). On Campus: integrating the university environment. In D. Baine, D. Sobsey, L. Wilgosh, \& G. M. Kysela (Eds.), Alternative futures for the education on students with severe disabilities (pp. 96-103). Edmonton: University of Alberta.

UN. (2007). Convention on the rights of persons with disabilities. Retrieved from https://www.un.org/development/desa/disabilities/convention-on-the-rights-of-persons-with-disabilities.htm 1 
Uusitalo-Malmivaara, L., Kankaanpää, P., Mäkinen, T., Raeluoto, T., Rauttu, K., Tarhala, V., \& Lehto, J. E. (2012). Are special education students happy? Scandinavian Journal of Educational Research, 56(4), 419-437. https://doi.org/10.1080/00313831.2011.599421

van Loon, J., Claes, C., Vandevelde, S. van Hove, G., \& Schalock, R. L. (2010). Assessing Individual Support Needs to Enhance Personal Outcomes. Exceptionality, (18), 193-202. https://doi.org/10.1080/09362835.2010.513924

\section{Copyrights}

Copyright for this article is retained by the author(s), with first publication rights granted to the journal.

This is an open-access article distributed under the terms and conditions of the Creative Commons Attribution license (http://creativecommons.org/licenses/by/4.0/). 